\title{
Acumulação de nutrientes em solos arenosos adubados com esterco bovino
}

\author{
Sandra Regina da Silva Galvão(1), Ignacio Hernan Salcedo ${ }^{(1)}$ e Fabio Freire de Oliveira ${ }^{(1)}$
}

(1)Universidade Federal de Pernambuco, Departamento de Energia Nuclear, Av. Prof.Luiz Freire, no 1000, Cidade Universitária, CEP $50740-540$
Recife, PE. E-mail: reginassg@uol.com.br, salcedo@ufpe.br, oliveiraff@yahoo.com.br

Resumo - Os objetivos deste trabalho foram quantificar as concentrações de carbono e nutrientes em solos de áreas adubadas e não adubadas com esterco; quantificar as concentrações de nutrientes em amostras de esterco bovino utilizado na região e calcular o acúmulo de nutrientes resultantes dessa adubação e o potencial de perdas por lixiviação. Foram amostradas 18 áreas agrícolas, com adição anual de esterco por pelo menos dois anos e, como controle, quatro áreas sob pastagem não adubadas, coletando-se amostras de solo das camadas de 0-20, 20-40 e 40-60 cm, que foram analisadas quanto à granulometria, densidade do solo, pH, C, N e P totais, bases trocáveis, $\mathrm{P}$ extraível por água e por Mehlich-1. Amostras de esterco utilizadas em nove áreas também foram analisadas. A aplicação de esterco resultou em acumulações médias ao redor de $20 \mathrm{Mg} \mathrm{ha}^{-1}$ de C, $2 \mathrm{Mg} \mathrm{ha}^{-1} \mathrm{de}$ $\mathrm{N}$ total e $\mathrm{Ca}$, e de 0,5 a $1 \mathrm{Mg} \mathrm{ha}^{-1}$ de $\mathrm{P}$ total, $\mathrm{K}$ e Mg $(0-60 \mathrm{~cm})$. Acumulações de $\mathrm{P}$ solúvel em água e bases trocáveis na camada de 40-60 cm, em relação às testemunhas, indicam grande potencial de perda desses nutrientes.

Termos para indexação: agricultura familiar, adubação orgânica, lixiviação de fósforo.

\section{Nutrient build up in sandy soils receiving manure additions}

\begin{abstract}
The objective of this work was to quantify changes on carbon and nutrient contents in soils under continuous manure additions. Eighteen cropped fields that had received annual additions of manure for at least two years and four fields under pasture with no history of manure addition were sampled to assess if this practice results in the accumulation or losses of added nutrients. Soils samples from the 0-20, 20-40 and 40-60 cm layers were taken from each field, and analyzed with regard to their physical (particle size and soil density) and chemical ( $\mathrm{pH}$, total $\mathrm{C}, \mathrm{N}$ and $\mathrm{P}$, extractable $\mathrm{P}$ by Mehlich-1 and water, and exchangeable cations) properties. Manure samples used in nine fields were also analyzed for chemical composition. Manure additions resulted in a build up of nutrient stocks near to $20 \mathrm{Mg} \mathrm{ha}^{-1}$ of C, $2 \mathrm{Mg} \mathrm{ha}^{-1}$ of $\mathrm{N}$ and $\mathrm{Ca}$, and 0.5 to $1 \mathrm{Mg} \mathrm{ha}^{-1}$ of $\mathrm{P}, \mathrm{K}$ and $\mathrm{Mg}(0-60 \mathrm{~cm})$. Water-soluble $\mathrm{P}$ concentrations of $7 \mathrm{mg} \mathrm{kg}^{-1}$ in the $40-60 \mathrm{~cm}$ layer indicated losses of this nutrient, the less mobile in soils. Accumulation of exchangeable cations in the 0-60 cm layer, in comparison with control areas, indicates an even greater potential for losses of these nutrients.
\end{abstract}

Index terms: subsistence agriculture, organic amendments, phosphorus lixiviation.

\section{Introdução}

A utilização de esterco é uma alternativa amplamente adotada para o suprimento de nutrientes, principalmente nitrogênio e fósforo, em áreas de agricultura familiar na região semi-árida e agreste do Nordeste do Brasil (Menezes \& Salcedo, 2007).

Em geral, os solos dessas regiões são deficientes em $\mathrm{N}$ e $\mathrm{P}$ e, por conseqüência, a produtividade, sem adubação, é muito limitada. O uso de fertilizantes inorgânicos é pouco freqüente devido ao limitado poder aquisitivo dos produtores de baixa renda, à dificuldade de acesso ao crédito agrícola e à elevada variabilidade na precipitação pluvial. Em culturas de maior rentabilidade, como a batatinha, é freqüente o uso de fertilizante nitrogenado comercial. Mais recentemente, tentou-se combinar a aplicação de esterco com a adubação verde (Silva et al., 2007), mas esta forma de manejo não tem sido amplamente adotada pelos agricultores.

As quantidades de esterco aplicadas são bastante variáveis em função do tipo de cultivo. No caso de áreas utilizadas com culturas mercantis, como batatinha (Solanum tuberosum) e erva-doce (Pimpinella 
anisum), as aplicações são anuais e em doses que podem variar entre 12 e $20 \mathrm{Mg} \mathrm{ha}^{-1}$. As áreas com cultivos de subsistência, com milho (Zea mays), feijãomulatinho (Phaseolus vulgaris), caupi (Vigna unguiculata), fava (Vicia faba) e mandioca (Manihot esculenta), podem receber aplicações anuais, ou em anos alternados, de doses que oscilam entre $4 \mathrm{e}$ $12 \mathrm{Mg} \mathrm{ha}^{-1}$ (Sabourin et al., 2000).

$\mathrm{O}$ aporte anual de $\mathrm{N}$ e $\mathrm{P}$ em áreas com culturas mercantis pode ser elevado: uma dose média de esterco de $16 \mathrm{Mg} \mathrm{ha}^{-1}$ (15\% umidade) com teores de $\mathrm{N}$ e $\mathrm{P}$ de 9 e $3 \mathrm{~g} \mathrm{~kg}^{-1}$ de matéria seca (MS), por exemplo, aportaria 116 e $40 \mathrm{~kg} \mathrm{ha}^{-1}$ desses nutrientes, respectivamente, para uma retirada de aproximadamente 54 e $3 \mathrm{~kg} \mathrm{ha}^{-1}$ de $\mathrm{Ne}$ $\mathrm{P}$ pela batatinha (Silva et al., 2007), com base na produtividade média de $6 \mathrm{Mg} \mathrm{ha}^{-1}$. Com isso, haveria um excesso anual de 62 e $37 \mathrm{~kg} \mathrm{ha}^{-1}$ de $\mathrm{N}$ e $\mathrm{P}$, respectivamente.

Observa-se, portanto, que aplicações contínuas nessas doses provavelmente estariam propiciando acúmulo de nutrientes no solo (Silva et al., 2007) e, muito possivelmente, sua migração vertical. Dados de perda de nutrientes por lixiviação são inexistentes na região, mas têm sido relatados em países com freqüentes adições de esterco (Sharpley et al., 2004). É possível que estas perdas aconteçam também na região do agreste devido a muitos dos solos que recebem esterco serem de textura arenosa (Galvão et al., 2005). Por esses motivos, um diagnóstico da intensidade de acumulação de nutrientes em áreas de solos arenosos com cultivos mercantis e de subsistência na região do agreste da Paraíba, normalmente adubadas com esterco, é importante para racionalizar o uso desse insumo.

Os objetivos deste trabalho foram quantificar as concentrações de carbono e nutrientes nas camadas de 0-20, 20-40 e 40-60 cm de áreas adubadas e não adubadas com esterco; quantificar as concentrações de nutrientes em amostras de esterco bovino utilizado na região e calcular o acúmulo de nutrientes resultante dessa adubação e o potencial de perdas por lixiviação.

\section{Material e Métodos}

Foram escolhidas 22 propriedades de agricultura familiar, representativas do Município de Esperança, no Agreste da Paraíba. Nessas propriedades, há pequenas áreas cultivadas com batatinha e erva-doce consorciadas, consideradas cultivos mercantis na região, além de roçados tradicionais de milho, feijãomulatinho, feijão-de-corda, mandioca e fava (Sabourin et al., 2000). O solo dominante nas áreas amostradas é o Neossolo Regolítico eutrófico (Embrapa, 1999), de textura arenosa a franco-arenosa, relevo ondulado a suave-ondulado. Nos anos de 2004-2006, a precipitação pluvial totalizou 1.121, 741 e $477 \mathrm{~mm}^{2} \mathrm{ano}^{-1}$, respectivamente, com sete meses ou mais de balanço hídrico negativo.

Histórico levantado junto aos produtores revelou que, das 22 áreas amostradas, 18 eram adubadas com esterco, enquanto quatro, com pastagens, não haviam sido adubadas. Quatorze das 18 áreas vinham sendo adubadas entre 15 e 40 anos, e quatro, durante menos de seis anos. As quantidades anuais de esterco curtido ( $15 \%$ umidade) aplicadas variavam entre $12 \mathrm{e}$ $20 \mathrm{Mg} \mathrm{ha}^{-1}$ (dose média de $16 \mathrm{Mg} \mathrm{ha}^{-1}$ ). Um agricultor aplicou $28 \mathrm{t} \mathrm{ha}^{-1}$ nos últimos dois anos.

$\mathrm{Na}$ maioria dos casos, o esterco foi comprado de fontes externas. Nas áreas de cultivo de batatinha, 13 dos 18 agricultores aplicaram fertilizantes comerciais nitrogenados (uréia e sulfato de amônio) em doses que variaram entre 32 e $67 \mathrm{~kg} \mathrm{ha}^{-1}$ de $\mathrm{N}$ (dose média de $55 \mathrm{~kg} \mathrm{ha}^{-1}$ ). A adubação orgânica e mineral é realizada no plantio da batatinha, mas esta cultura é normalmente precedida por um cultivo de feijão, dependendo da época de início das chuvas. Em anos de boa disponibilidade hídrica, pode haver um plantio de caupi após a colheita da batatinha, mas esse plantio dificilmente alcança o estágio de formação de grãos e é utilizado como forragem.

Os agricultores não possuem registros precisos de médio ou longo prazo relacionados com o manejo, doses de esterco aplicadas ou com a sequiência das culturas. Os cultivos implementados variaram de ano para ano, em função da disponibilidade de sementes, dos preços agrícolas e da percepção quanto à precipitação pluvial; da mesma forma, as doses dos insumos utilizados (esterco ou adubo mineral) também variaram em função da disponibilidade financeira do agricultor e do preço desses insumos. Por esses motivos não se apresentam dados de históricos individuais, e a análise é baseada em valores médios das áreas amostradas.

Em áreas cultivadas com o consórcio batatinha/ervadoce (normalmente cinco leirões de batatinha para cada leirão de erva-doce), foram obtidas amostras simples de solo das camadas de 0-20, 20-40, e 40-60 cm, em dez leirões de batatinha separados entre si por quatro leirões de batatinha e um de erva-doce. 
As amostras simples de solo foram secas ao ar e passadas por peneira de $2 \mathrm{~mm}$; massas iguais de solo de cada amostra simples foram homogeneizadas para compor uma amostra composta de cada camada. Nestas amostras compostas de solo, foram determinados os teores de areia, silte e argila pelo método do densímetro; densidade do solo e pH em água (1:2,5) de acordo com os métodos da Embrapa (1997). Os teores de P e K extraíveis com Mehlich-1 foram quantificados por colorimetria e fotometria de chama, respectivamente (Embrapa, 1997). O teor de $\mathrm{P}$ extraível por água foi determinado segundo o método de Ohno \& Zibilske (1991). O Ca e o Mg trocáveis foram extraídos com $\mathrm{KCl} 1 \mathrm{~mol} \mathrm{~L}^{-1}$ e quantificados por espectrofotometria de absorção atômica (Embrapa, 1997). Subamostras foram passadas em peneira de malha de $0,149 \mathrm{~mm}$ para análise de $\mathrm{C}$ orgânico por oxidação úmida, $\mathrm{N}$ total ( $\mathrm{N}$ orgânico mais $\mathrm{N}$ mineral), pelo método de Kjeldahl (Embrapa, 1997) e P total, por colorimetria, após digestão com mistura de $\mathrm{H}_{2} \mathrm{SO}_{4}$ concentrado e $\mathrm{H}_{2} \mathrm{O}_{2}$ (Thomas et al., 1967).

Amostras de esterco foram coletadas em nove das 18 áreas, com a finalidade de quantificar os teores de $\mathrm{N}, \mathrm{P}, \mathrm{K}, \mathrm{Ca}$ e $\mathrm{Mg}$ aportados pelo esterco. Uma subamostra de esterco, coletada de cada área, foi seca em estufa de ventilação forçada de ar a $65^{\circ} \mathrm{C}$, passada em moinho e digerida com uma mistura de $\mathrm{H}_{2} \mathrm{SO}_{4}$ concentrado e $\mathrm{H}_{2} \mathrm{O}_{2}$ (Thomas et al., 1967). No digerido, determinou-se $\mathrm{N}$ por destilação com arraste de vapor, $\mathrm{P}$ por colorimetria, $\mathrm{K}, \mathrm{Ca}$ e $\mathrm{Mg}$ por espectrofotometria de absorção atômica (Embrapa, 1997). Determinaram-se também os teores de celulose, hemicelulose, lignina e cinzas (Van Soest, 1963).

O efeito da adubação com esterco na acumulação de nutrientes no solo, em cada profundidade, foi avaliado pelo teste t de Student, comparando-se as médias das áreas adubadas com as das áreas não adubadas.

Por tratar-se do nutriente menos móvel e o mais deficiente nos solos da região semi-árida (Salcedo, 2006), o deslocamento vertical de $\mathrm{P}$ foi avaliado de forma mais detalhada: as 22 áreas foram agrupadas em quatro faixas, com base na concentração de $\mathrm{P}$ total na camada de $0-20 \mathrm{~cm}$. A faixa $1\left(\mathrm{P} \leq 110 \mathrm{mg} \mathrm{kg}^{-1}\right)$ incluiu quatro amostras das áreas não adubadas, enquanto nas adubadas, nove ficaram distribuídas na faixa $2\left(\mathrm{P}=111-220 \mathrm{mg} \mathrm{kg}^{-1}\right)$, cinco na faixa $3\left(\mathrm{P}=221-330 \mathrm{mg} \mathrm{kg}^{-1}\right)$ e quatro na faixa 4 $\left(\mathrm{P}=331-440 \mathrm{mg} \mathrm{kg}^{-1}\right)$. As amostras das duas camadas seguintes mantiveram-se no mesmo grupo atribuído às da primeira camada.
As diferenças entre as quatro faixas mencionadas em relação aos teores de $\mathrm{P}$ total, nas camadas de 20-40 e 40-60 cm, e de P solúvel em água, nas camadas de 0-20, 20-40 e 40-60 cm, foram submetidas à análise de variância para cada profundidade, e as médias comparadas pelo teste HSD Tukey, a 5\% de probabilidade, para número desigual de repetições. Devido à falta de homogeneidade das variâncias nos teores de P solúvel em água (teste de Levene), a análise estatística foi realizada com os dados transformados para $\log (\mathrm{x})$ (Schabenberger \& Pierce, 2002).

Foi verificado se a acumulação média de nutrientes nas áreas adubadas $(0-60 \mathrm{~cm})$ guardava relação com o intervalo de anos de adubação informado pelos agricultores (entre 15 e 40 anos); para isso, foram calculadas as entradas de cada nutriente, com base numa composição média do esterco das propriedades e em uma dose média de $16 \mathrm{Mg} \mathrm{ha}^{-1}$ de esterco (85\% MS) e $55 \mathrm{~kg} \mathrm{ha}^{-1}$ de $\mathrm{N}$ como fertilizante comercial, com base em informações dos produtores. A estimativa de retiradas (saídas) de nutrientes foi baseada em valores médios de produtividade da sequiência feijão-batatinha, de 1.285 e $500 \mathrm{~kg} \mathrm{ha}^{-1}$ para palha e grão de feijão, respectivamente, e de $6.000 \mathrm{~kg} \mathrm{ha}^{-1}$ para batatinha, e em dados de composição química dessas culturas, que foram os seguintes, feijão: $\mathrm{N}=1,9$ e 3,93\%, $\mathrm{P}=0,22 \mathrm{e}$ $0,34 \%, \mathrm{~K}=1,8$ e $1,12 \%, \mathrm{Ca}=0,80$ e $0,62 \%, \mathrm{Mg}=0,4 \mathrm{e}$ $0,85 \%$ para palha e grão, respectivamente, e batatinha: $\mathrm{N}=0,9 \%, \mathrm{P}=0,05 \%, \mathrm{~K}=1,3 \%, \mathrm{Ca}=0,08 \% \mathrm{e}$ $\mathrm{Mg}=0,06 \%$ para o tubérculo (Yorinori, 2003; Andrade et al., 2004; Sampaio et al., 2004; Silva et al., 2007); a extração pelo caupi após a batatinha não foi computada devido à baixa freqüência desse plantio.

\section{Resultados e Discussão}

A aplicação contínua de esterco proporcionou aumento significativo no $\mathrm{pH}$ e nos teores de todos os elementos na camada de $0-20 \mathrm{~cm}$, em relação às áreas não adubadas (Tabela 1). Nas camadas de 20-40 e 40-60 cm, apenas os teores de C e $\mathrm{N}$ não apresentaram aumentos significativos com a aplicação de esterco. Os teores de $\mathrm{P}, \mathrm{Ca}, \mathrm{Mg}$ e $\mathrm{K}$ disponíveis dos solos adubados foram classificados como altos, segundo o manual de sugestão de adubação da Empresa de Assistência Técnica e Extensão Rural (1979), em decorrência dos aportes desses nutrientes pelo esterco (Tabela 2). 
Os teores de nutrientes nas amostras de esterco foram muito variáveis e apresentaram a seguinte ordem: $\mathrm{Ca}>\mathrm{K}>\mathrm{N}>\mathrm{Mg}>\mathrm{P}$ (Tabela 2). Na maioria das pesquisas que utilizaram esterco bovino, $\mathrm{o} \mathrm{N}$ apresentou o maior teor (Cassol et al., 2001), mas em alguns casos o teor de $\mathrm{Ca}$ foi maior, ou se assemelhou ao teor de $\mathrm{N}$ (Sharpley et al., 2004). Além do N, os demais nutrientes no esterco também apresentaram baixos teores (Tabela 2), quando comparados com valores encontrados em outros trabalhos (Cassol et al., 2001; Ajiboye et al., 2004; Sharpley et al., 2004).

$\mathrm{A}$ adição do esterco geralmente não modifica o $\mathrm{pH}$ do solo, mas quando há uma aplicação contínua do adubo orgânico poderá ocorrer aumento significativo do $\mathrm{pH}$ (Mitchell \& Tu, 2006). Os aumentos do pH em água oscilaram entre 0,5 e 1 unidade (Tabela 1 ), provavelmente devido ao aporte de $\mathrm{Ca}$ (Tabela 2) em conjunto com o efeito tampão de bicarbonatos e ácidos orgânicos, proporcionados pela adição do esterco por longos períodos (Sharpley \& Moyer, 2000; Eghball, 2002).

$\mathrm{O}$ teor médio de $\mathrm{C}$ das áreas adubadas foi quase o dobro das não adubadas, na camada de $0-20 \mathrm{~cm}$, e aumentou entre 20 e $30 \%$ nas duas camadas seguintes, mas sem atingir significância estatística. O esterco continha um teor médio (14\%) de lignina (Tabela 2), substância de lenta decomposição e precursora de substâncias húmicas (Vanlauwe et al., 2005), o que deve ter contribuído com os acréscimos de $\mathrm{C}$ observados ao longo do tempo.

$\mathrm{O} \mathrm{N}$ da matéria orgânica apresentou a mesma tendência que o $\mathrm{C}$, mas o acréscimo foi um pouco maior (Tabela 1), o que estreitou a relação C:N nas áreas adubadas, em relação às não adubadas, tendência observada nas três camadas. Em solos com textura semelhante, Woods \& Schuman (1988) observaram estreitamento na relação C:N após um período de 25 anos de cultivo, comparando-os com solos sob pastagem nativa. Fraga \& Salcedo (2004), em solos do semi-árido nordestino com mais de 20 anos de cultivo, também observaram estreitamento da relação $\mathrm{C}: \mathrm{N}$, em áreas cultivadas degradadas, em relação a áreas nativas adjacentes.

O P disponível nas áreas adubadas aumentou $20(0-20 \mathrm{~cm}), 22(20-40 \mathrm{~cm})$ e 25 vezes $(40-60 \mathrm{~cm}) \mathrm{em}$ relação às não adubadas (Tabela 1), devido ao teor médio elevado de P no esterco utilizado na região (Tabela 2), e ao fato de uma elevada proporção do P no esterco estar em formas disponíveis (Cassol et al., 2001; Ajiboye et al., 2004). A deficiência de $P$ é intensa e generalizada na região. Oito áreas sob plantio de mandioca, em solos

Tabela 1. Atributos físicos e químicos de amostras de solo coletadas em três profundidades de áreas com e sem aplicação de $\operatorname{esterco~}^{(1)}$.

\begin{tabular}{|c|c|c|c|c|c|c|c|c|c|c|c|c|}
\hline \multirow[t]{2}{*}{ Aplicação de esterco } & Areia & Silte & Argila & Ds & $\mathrm{pH}$ & \multicolumn{2}{|c|}{$\begin{array}{c}\mathrm{COT} \\
\mathrm{CO}\end{array}$} & $\mathrm{P}$ ex & P total & $\mathrm{K}$ & \multicolumn{2}{|c|}{$\begin{array}{cc}\mathrm{Ca} & \mathrm{Mg} \\
---\left(\mathrm{cmol}_{\mathrm{c}} \mathrm{kg}^{-1}\right) & -- \\
\end{array}$} \\
\hline & \multicolumn{12}{|c|}{$0-20 \mathrm{~cm}$} \\
\hline Sim & 861 & 100 & 39 & 1,53 & $6,7 \mathrm{a}$ & $8,5 \mathrm{a}$ & $0,87 \mathrm{a}$ & $74 a$ & $274 a$ & $141 \mathrm{a}$ & $1,70 \mathrm{a}$ & $0,71 \mathrm{a}$ \\
\hline Não & 839 & 112 & 49 & 1,54 & $5,5 \mathrm{~b}$ & $3,9 \mathrm{~b}$ & $0,33 \mathrm{~b}$ & $3,8 \mathrm{~b}$ & $86 \mathrm{~b}$ & $63 \mathrm{~b}$ & $0,55 \mathrm{~b}$ & $0,18 \mathrm{~b}$ \\
\hline & \multicolumn{12}{|c|}{$20-40 \mathrm{~cm}$} \\
\hline Sim & 793 & 146 & 61 & 1,49 & $6,3 \mathrm{a}$ & $5,1 \mathrm{a}$ & $0,51 \mathrm{a}$ & $41 \mathrm{a}$ & $195 \mathrm{a}$ & $117 \mathrm{a}$ & $1,60 \mathrm{a}$ & $0,66 \mathrm{a}$ \\
\hline Não & 822 & 98 & 80 & 1,54 & $5,3 \mathrm{~b}$ & $3,8 \mathrm{a}$ & $0,32 \mathrm{a}$ & $1,8 \mathrm{~b}$ & $83 \mathrm{~b}$ & $26 \mathrm{~b}$ & $0,37 \mathrm{~b}$ & $0,17 \mathrm{~b}$ \\
\hline \multicolumn{13}{|c|}{$40-60 \mathrm{~cm}$} \\
\hline Sim & 778 & 156 & 66 & 1,50 & $6,0 \mathrm{a}$ & $4,1 \mathrm{a}$ & $0,44 \mathrm{a}$ & $26 a$ & $155 \mathrm{a}$ & $103 a$ & $1,40 \mathrm{a}$ & $0,63 a$ \\
\hline Não & 817 & 107 & 76 & 1,55 & $5,4 \mathrm{a}$ & $3,5 \mathrm{a}$ & $0,29 \mathrm{a}$ & $1,1 \mathrm{~b}$ & $75 b$ & $36 \mathrm{~b}$ & $0,36 \mathrm{~b}$ & $0,14 \mathrm{~b}$ \\
\hline
\end{tabular}

${ }^{(1)}$ Médias seguidas por mesma letra na coluna não diferem entre si a 5\% de probabilidade, pelo teste de Student; Ds, densidade do solo; COT, carbono orgânico total; Nt, nitrogênio total; P ex, P extraível por Mehlich-1; os valores de $\mathrm{K}$, Ca e Mg referem-se às quantidades extraíveis e trocáveis no solo.

Tabela 2. Teor médio, mínimo, máximo, desvio-padrão e coeficiente de variação para N, P, K, Ca, Mg, cinzas, celulose, hemicelulose e lignina, em nove amostras de esterco bovino coletadas em nove propriedades do Município de Esperança, PB.

\begin{tabular}{|c|c|c|c|c|c|}
\hline Nutriente & Média & Mínimo & Máximo & Desvio-padrão & Coeficiente de variação \\
\hline $\mathrm{N}\left(\mathrm{g} \mathrm{kg}^{-1}\right)$ & 8,7 & 4,6 & 18 & 4,0 & 46 \\
\hline $\mathrm{P}\left(\mathrm{g} \mathrm{kg}^{-1}\right)$ & 3,0 & 1,6 & 5,9 & 1,6 & 54 \\
\hline $\mathrm{K}\left(\mathrm{g} \mathrm{kg}^{-1}\right)$ & 12 & 4,2 & 28 & 8,1 & 67 \\
\hline $\mathrm{Ca}\left(\mathrm{g} \mathrm{kg}^{-1}\right)$ & 14 & 6,2 & 26 & 6,3 & 45 \\
\hline $\operatorname{Mg}\left(\mathrm{g} \mathrm{kg}^{-1}\right)$ & 5,3 & 2,9 & 7,5 & 1,7 & 32 \\
\hline Cinzas $(\%)$ & 56 & 41 & 72 & 22 & 38 \\
\hline Celulose $(\%)$ & 11 & 6,7 & 16 & 3,8 & 33 \\
\hline Hemicelulose (\%) & 8,1 & 3,4 & 16 & 4,1 & 51 \\
\hline Lignina $(\%)$ & 14 & 8,8 & 18 & 3,8 & 28 \\
\hline
\end{tabular}


arenosos sem adubação, apresentaram teor médio de P Mehlich-1 inferior a $4 \mathrm{mg} \mathrm{kg}^{-1}$ de solo (Costa, 2007) e, em microbacia com 800 ha de extensão nos municípios de Areia e Remígio, 133 amostras sob pastagem apresentaram 2,5 $\mathrm{mg} \mathrm{kg}^{-1}$ de P (Mehlich-1), ao passo que 127 amostras sob capineira e roçado continham $5,9 \mathrm{mg} \mathrm{kg}^{-1}$; aumento significativo causado por adições ocasionais de esterco (Santos, 2004).

Os aumentos significativos no teor de $\mathrm{P}$ total nas camadas de 20-40 e 40-60 cm, em relação às áreas não adubadas (Figura 1), indicam deslocamento vertical de P. O P solúvel em água, observado nas amostras, corrobora esse deslocamento, uma vez que os teores ao redor de $7 \mathrm{mg} \mathrm{kg}^{-1}$ na camada mais profunda $(40-60 \mathrm{~cm}$ ) foram significativamente maiores que nas áreas não adubadas (Figura 2). Esse $\mathrm{P}$ solúvel em água fica susceptível à lixiviação por chuvas intensas. A baixa capacidade de adsorção de $\mathrm{P}$ de solos arenosos (Rheinheimer et al., 2003) pode contribuir para esse deslocamento vertical. Em relação às formas químicas de $\mathrm{P}$, a literatura indica tanto o deslocamento em formas inorgânicas (Chardon et al., 2007) quanto orgânicas (Djodjic et al., 2004). Deve-se considerar que a maior parte do $\mathrm{P}$ contido no esterco está em formas inorgânicas (P-resina) (Cassol et al., 2001). A contaminação dos lençóis freáticos com $P$ é um tema atual em vários países que utilizam este insumo, uma vez que a dose de esterco a ser aplicada baseia-se na necessidade de $\mathrm{N}$ das

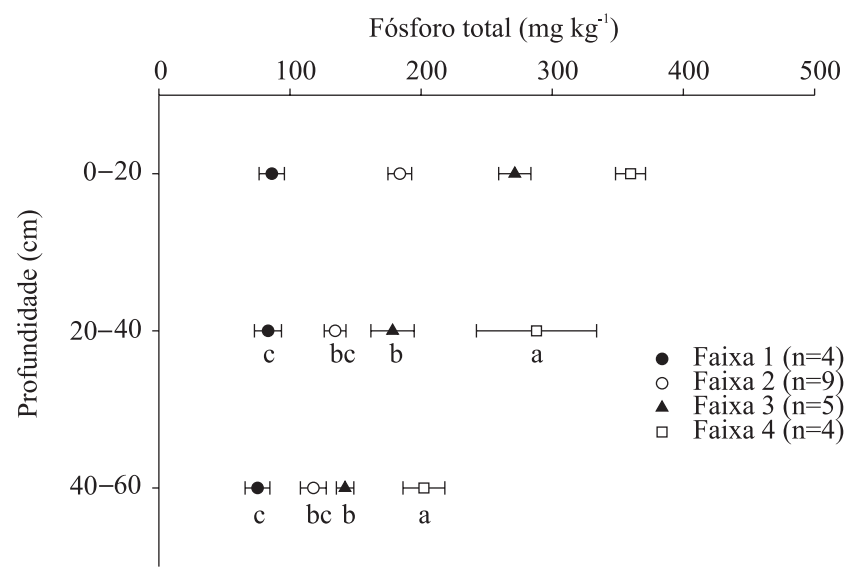

Figura 1. Teor médio e erro-padrão de $\mathrm{P}$ total em amostras de solo agrupadas em quatro faixas, de acordo com o teor de $\mathrm{P}$ total na camada de $0-20 \mathrm{~cm}$ (faixa $1: \leq 110$; faixa $2: 111-220$; faixa 3: 221-330; faixa 4: 331-440 $\mathrm{mg} \mathrm{kg}^{-1}$ ). Médias com mesma letra, em uma mesma profundidade, não diferem entre si pelo teste de Tukey, a 5\% de probabilidade. culturas, o que pode propiciar a adição excessiva de $\mathrm{P}$ ao solo (Griffin et al., 2003; Ajiboye et al., 2004; Djodjic et al., 2004).

Considerando que o detalhamento do deslocamento vertical realizado foi feito para um nutriente de baixa mobilidade (Figuras 1 e 2), é possível inferir que os acréscimos significativos nos teores de K extraível e Ca e Mg trocáveis em profundidade (Tabela 1) estejam indicando perdas desses cátions por drenagem bem maiores que as de $\mathrm{P}$.

Os estoques médios de nutrientes na camada de 0-60 cm do solo das áreas adubadas e não adubadas com esterco foram calculados com base nos dados da Tabela 1 e mostraram acumulação elevada de C $\left(18,9 \mathrm{Mg} \mathrm{ha}^{-1}\right)$ e nutrientes, na ordem de $2 \mathrm{Mg} \mathrm{ha}^{-1}$ para o $\mathrm{N}$ total e $\mathrm{Ca}$, e de menos de $1 \mathrm{Mg} \mathrm{ha}^{-1}$ para os demais nutrientes (Tabela 3). A relação $\mathrm{C}: \mathrm{N}$ das quantidades acumuladas é muito próxima da relação $\mathrm{C}: \mathrm{N}$ da matéria orgânica dos solos adubados (Tabela 1). Acumulações de $\mathrm{N}$ total, P total e K extraível na camada de $0-20 \mathrm{~cm}$ de solo cultivado com batatinha e adubado anualmente com esterco ou esterco e adubação química, durante cinco anos, também foram observados por Silva et al. (2007).

No balanço realizado entre entradas e saídas de nutrientes no solo, as saídas foram menores que os aportes, o que resultou em saldos positivos anuais para todos os nutrientes (Tabela 3). O cálcio apresentou maior

Fósforo solúvel em água ( $\left.\mathrm{mg} \mathrm{kg}^{-1}\right)$

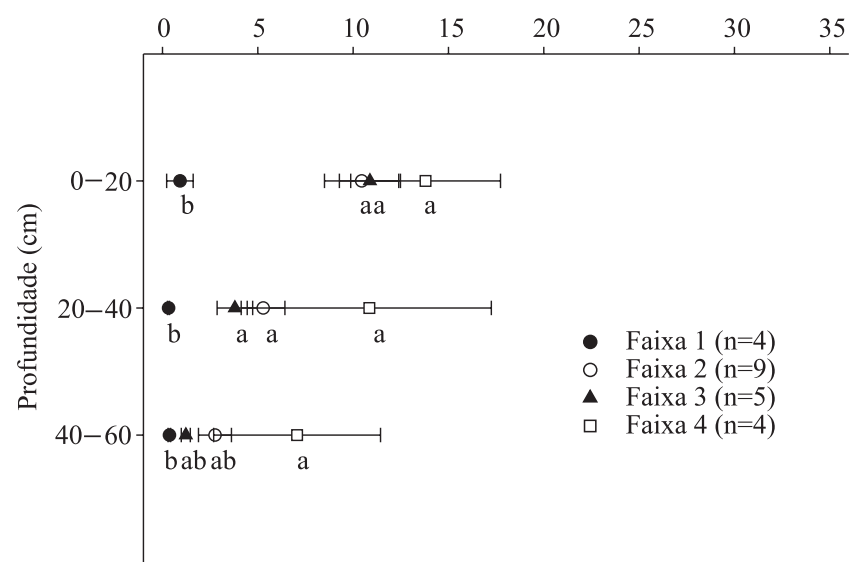

Figura 2. Teores médios e erro-padrão de P solúvel em água em amostras de solo agrupadas em quatro faixas, de acordo com o teor de P total na camada de $0-20 \mathrm{~cm}$ (faixa 1: $\leq 110$; faixa 2: 111-220; faixa 3: 221-330; faixa 4: 331-440 $\mathrm{mg} \mathrm{kg}^{-1}$ ). Médias com mesma letra, em uma mesma profundidade, não diferem entre si pelo teste de Tukey, a $5 \%$ de probabilidade. 
Tabela 3. Estoque e balanço anual estimado de nutrientes na camada de $0-60 \mathrm{~cm}$, em solos adubados, ou não, com esterco bovino, e perdas estimadas acumuladas (30 anos) nas áreas adubadas.

\begin{tabular}{|c|c|c|c|c|c|c|c|}
\hline \multirow[t]{2}{*}{ Nutriente } & \multicolumn{3}{|c|}{ Estoque $^{(1)}$} & \multicolumn{3}{|c|}{ Balanço anual } & \multirow[t]{2}{*}{ Perdas estimadas } \\
\hline & Não adubado & Adubado & Acumulação & Entrada $^{(2)}$ & Saída ${ }^{(3)}$ & Saldo anual & \\
\hline & \multicolumn{3}{|c|}{ 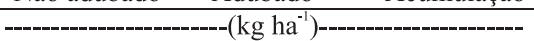 } & \multicolumn{2}{|c|}{------------(kg ha' $\left.{ }^{-1}\right)------------$} & $\left(\mathrm{kg} \mathrm{ha}^{-1} \mathrm{ano}^{-1}\right)$ & $\left(\mathrm{kg} \mathrm{ha}^{-1}\right)$ \\
\hline P total & 734 & 1.707 & 973 & 40 & 8 & 32 & 0 \\
\hline $\mathrm{N}$ total & 2.920 & 4.952 & 2.032 & 171 & 98 & 73 & -153 \\
\hline K Mehlich & 397 & 1.031 & 634 & 160 & 107 & 53 & -962 \\
\hline Ca trocável & 798 & 2.907 & 2.109 & 186 & 18 & 168 & -2.919 \\
\hline Mg trocável & 185 & 719 & 534 & 71 & 13 & 58 & -1.204 \\
\hline
\end{tabular}

${ }^{(1)}$ Os estoques foram calculados com base nos dados da Tabela 1. ${ }^{(2)}$ Baseado no teor médio da Tabela 2 e em dose média anual de 16 Mg ha-1 de esterco curtido (85\% matéria seca) $+55 \mathrm{~kg} \mathrm{ha}^{-1}$ de $\mathrm{N}$ de fertilizante comercial. (3)Extração de nutrientes por batata (produtividade de tubérculos $=6.000 \mathrm{~kg} \mathrm{ha}^{-1}$ ) e feijão-comum (produtividade de palha $=1.285 \mathrm{~kg} \mathrm{ha}^{-1}$ e de grão $=500 \mathrm{~kg} \mathrm{ha}^{-1}$ ).

saldo positivo em relação aos demais nutrientes $\left(168 \mathrm{~kg} \mathrm{ha}^{-1}\right.$ ano $\left.^{-1}\right)$ em virtude de sua elevada concentração nos estercos da região (Tabela 2) e baixa exportação pela batatinha $\left(5 \mathrm{~kg} \mathrm{ha}^{-1}\right)$ (Yorinori, 2003) e pelo feijão (13 $\left.\mathrm{kg} \mathrm{ha}^{-1}\right)$ (Andrade et al., 2004; Sampaio et al., 2004). O N foi o segundo nutriente adicionado em excesso, provavelmente devido ao uso adicional de fertilizantes comerciais no cultivo da batatinha.

Com um excesso anual de P de $32 \mathrm{~kg} \mathrm{ha}^{-1} \mathrm{ano}^{-1}$ (Tabela 3) seriam necessários pelo menos 30 anos para atingir a acumulação observada de $973 \mathrm{~kg} \mathrm{ha}^{-1}$ na camada de 0-60 cm. Este período fica dentro dos intervalos de cultivo na região relatados pelos agricultores. Multiplicando-se os saldos anuais dos demais nutrientes por 30 anos, observa-se que as acumulações teóricas foram maiores que os estoques acumulados determinados experimentalmente (Tabela 3). As quantidades excedentes foram interpretadas como perdas por drenagem profunda. Embora os valores absolutos dessas estimativas devam ser considerados com cautela, em virtude das variações nas entradas e nas saídas ao longo desse período de 30 anos ou mais, as estimativas não deixam dúvidas quanto à ocorrência de perdas consideráveis de nutrientes nas condições médias de manejo na região.

Admitindo-se que as perdas relativas entre nutrientes sejam as indicadas na Tabela 3, chama a atenção o fato de o $\mathrm{N}$ aparecer como o segundo nutriente mais acumulado nesses solos arenosos. A entrada anual média de $\mathrm{N}$ é de $171 \mathrm{~kg} \mathrm{ha}^{-1}$, sendo que $116 \mathrm{~kg} \mathrm{ha}^{-1} \mathrm{em}$ forma orgânica (esterco) e $55 \mathrm{~kg} \mathrm{ha}^{-1} \mathrm{em}$ forma mineral, que apresenta maior potencial de lixiviação. Entretanto, em experimento de incubação de esterco, Menezes \& Salcedo (2007) observaram imobilização de N no solo 60 dias após sua adição. Em experimentos de campo com batatinha (5 anos), adubada com esterco ou esterco
+ Crotalaria juncea, as maiores retiradas de $\mathrm{N}$ pela cultura foram proporcionadas pela última combinação (Silva et al., 2007), indício de que a adição de esterco combinada com uma fonte lábil diminui a probabilidade de perdas desse nutriente.

Em relação às bases trocáveis, era esperado que apresentassem perdas elevadas, considerando-se a textura arenosa e a baixa capacidade de troca desses solos.

O esterco é um recurso escasso na região e tanto pode ser uma fonte de renda para o agricultor, no caso de venda do produto, como um meio de repor ao solo os nutrientes retirados pelas culturas. Os resultados indicam a necessidade premente de estudos para otimizar as doses de utilização assim como para avaliar o efeito residual dos nutrientes aportados por esse insumo.

\section{Conclusões}

1. A quantidade de nutrientes adicionados anualmente pelo esterco na região excede as exigências das culturas e resulta em acumulações significativas de $\mathrm{C}, \mathrm{N}, \mathrm{P}, \mathrm{K}$, $\mathrm{Ca}$ e $\mathrm{Mg}$ na camada de $0-20 \mathrm{~cm}$.

2. Uma parte do acúmulo de $\mathrm{P}$ total, P-Mehlich e P solúvel em água, além de $\mathrm{K}, \mathrm{Ca}$ e $\mathrm{Mg}$, encontra-se nas camadas de 20-40 e 40-60 cm, indicando migração vertical desses nutrientes e potencial de perdas por drenagem profunda.

\section{Agradecimentos}

Aos funcionários do Laboratório de Fertilidade de Solos do grupo de Radioagronomia, pela ajuda nas análises; ao Inter-American Institute for Global Change e ao $\mathrm{CNPq}$, pelo apoio financeiro; aos agricultores responsáveis pelas áreas estudadas, por terem facilitado o trabalho de amostragem. 


\section{Referências}

AJIBOYE, B.; AKINREMI, O.O.; RACZ, G.J. Laboratory characterization of phosphorus in fresh and oven-dried organic amendments. Journal of Environmental Quality, v.33, p.10621069, 2004.

ANDRADE, C.A.B.; PATRONI, S.M.S.; CLEMENTE, E.; SCAPIM, C.A. Produtividade e qualidade nutricional de cultivares de feijão em diferentes adubações. Ciência Agrotécnica, v.28, p.1077-1086, 2004.

CASSOL, P.C.; GIANELLO, C.; COSTA, V.E.U. Frações de fósforo em estrumes e sua eficiência como adubo fosfatado. Revista Brasileira de Ciência do Solo, v.25, p.635-644, 2001.

CHARDON, W.J.; AALDERINK, G.H.; SALM, van der C. Phosphorus leaching from cow manure patches on soil columns. Journal of Environmental Quality, v.36, p.17-22, 2007.

COSTA, A.A. Diagnóstico da fertilidade do solo para a cultura da mandioca (Manihot esculenta, Crantz) na mesorregião do agreste paraibano. 2007. 40p. Dissertação (Mestrado) Universidade Federal da Paraíba, Areia.

DJODJIC, F.; BÖRLING, K.; BERGSTRÖM, L. Phosphorus leaching in relation to soil type and soil phosphorus content. Journal of Environmental Quality, v.33, p.678-684, 2004.

EGHBALL, B. Soil properties as influenced by phosphorus- and nitrogen-based manure and compost applications. Agronomy Journal, v.94, p.128-135, 2002.

EMBRAPA. Manual de métodos de análise de solo. 2.ed. Rio de Janeiro: Embrapa-CNPS, 1997. 212p.

EMBRAPA. Sistema brasileiro de classificação de solos. Brasília: Embrapa-SPI; Rio de Janeiro: Embrapa-CNPS, 1999. 412p.

EMPRESA DEASSISTÊNCIA TÉCNICA E EXTENSÃO RURAL (João Pessoa, PB). Manual de sugestão de adubação para o Estado da Paraíba: primeira aproximação. João Pessoa: Emater, 1979. 105p. FRAGA, V. da S.; SALCEDO, I.H. Declines of organic nutrient pools in tropical semi-arid soils under subsistence farming. Soil Science Society of America Journal, v.68, p.215-224, 2004.

GALVÃO, S.R.S.; SALCEDO, I.H.; SANTOS, A.C. Frações de carbono e nitrogênio em função da textura, do relevo e do uso do solo na microbacia do Agreste em Vaca Brava (PB). Revista Brasileira de Ciência do Solo, v.29, p.955-962, 2005.

GRIFFIN, T.S.; HONEYCUTT, C.W.; HE, Z. Changes in soil phosphorus from manure application. Soil Science Society of America Journal, v.67, p.645-653, 2003.

MENEZES, R.S.C.; SALCEDO. I.H. Mineralização de N após incorporação de adubos orgânicos em um Neossolo Regolítico cultivado com milho. Revista Brasileira de Engenharia Agrícola e Ambiental, v.11, p.361-367, 2007.

MITCHELL, C.C.; TU, S. Nutrient accumulation and movement from poultry litter. Soil Science Society of America Journal, v.70, p.2146-2153, 2006.

OHNO, T.; ZIBILSKE, L.M. Determination of low concentrations of phosphorus in soil extracts using malachite green. Soil Science Society of America Journal, v.55, p.892-895, 1991.
RHEINHEIMER, D.S.; ANGHINONI, I.; CONTE, E.; KAMINSKI, J.; GATIBONI, L.C. Dessorção de fósforo avaliada por extrações sucessivas em amostras de solo provenientes dos sistemas plantio direto e convencional. Ciência Rural, v.33, p.10531059, 2003.

SABOURIN, E.; SILVEIRA, L.M.; TONNEAU, J.P.; SIDERSKY, $P$. Fertilidade e agricultura familiar no Agreste Paraibano: um estudo sobre o manejo da biomassa. Esperança: Cirad-Terra/ASPTA, 2000. 59p.

SALCEDO, I.H. Biogeoquímica do fósforo em solos da região semiárida do NE do Brasil. Revista de Geografia, v.23, p.108-123, 2006.

SAMPAIO, E.V.S.B.; TIESSEN, H.; ANTONINO, A.C.D.; SALCEDO, I.H. Residual N and P fertilizer effect and fertilizer recovery on intercropped and sloe-cropped corn and beans in semiarid northeast Brazil. Nutrient Cycling in Agroecosystems, v.70, p.111, 2004.

SANTOS, A.C. Fertilidade de solo e redistribuição de ${ }^{137} \mathrm{Cs}$ em função da cobertura vegetal, relevo e classes texturais, em uma bacia hidrográfica do Estado da Paraíba. 2004. 67p. Tese (Doutorado) - Universidade Federal de Pernambuco.

SCHABENBERGER, O.; PIERCE, F.J. Contemporary statistical models for the plant and soil sciences. Boca Raton: CRC Press, 2002, 753p.

SHARPLEY, A.N.; MOYER, B. Phosphorus forms in manure and compost and their release during simulated rainfall. Journal of Environmental Quality, v.29, p.1462-1469, 2000.

SHARPLEY, A.N.; McDOWELL, R.W.; KLEINNMAN, J.A. Amounts, forms, and solubility of phosphorus in soils receiving manure. Soil Science Society of America Journal, v.68, p.20482057, 2004.

SILVA, T.O.; MENEZES, R.S.C.; TIESSEN, H.; SAMPAIO, E.V.S.B.; SALCEDO, I.H.; SILVEIRA, L.M. Adubação orgânica da batata com esterco e/ou Crotalaria juncea. I - Produtividade vegetal e estoque de nutrientes no solo em longo prazo. Revista Brasileira de Ciência do Solo, v.31, p.39-49, 2007.

THOMAS, R.L.; SHEARD, R.W.; MOYER, J.R. Comparison of conventional and automated procedures for nitrogen, phosphorus and potassium analysis of plant material using a single digest. Agronomy Journal, v.59, p.240-243, 1967.

VAN SOEST, P.J. Use of detergents in the analysis of fibrous feeds. II. A rapid method for the determination of fiber and lignin. Journal of the Association of Official Agricultural Chemists, v.46, p.829835, 1963.

VANLAUWE, B.; GACHENGO, C.; SHEPHERD, K.; BARRIOS, E.; CADISCH, G.; PALM, C.A. Laboratory validation of a resource quality-based conceptual framework for organic matter management. Soil Science Society of America Journal, v.69, p.1135-1145, 2005.

WOODS, L.E.; SCHUMAN, G.E. Cultivation and slope position effects on soil organic matter. Soil Science Society of America Journal, v.52, p.1371-1376, 1988.

YORINORI, G.T. Curva de crescimento e acúmulo de nutrientes pela cultura da batata cv. Atlantic. 2003. 66p. Dissertação (Mestrado) - Escola Superior de Agricultura Luiz de Queiroz, Piracicaba. 